IRSTI $34.23 .41 ; 34.35 .17 ; 68.03 .03$

\author{
${ }^{1 *}$ A.Y. Amalova, ${ }^{1,2}$ K.A. Yermekbayev, \\ ${ }^{2}$ S. Griffiths, ${ }^{1}$ S.I. Abugalieva, ${ }^{1}$ Y.K. Turuspekov \\ ${ }^{1}$ Institute of Plant Biology and Biotechnology, Almaty, Kazakhstan \\ ${ }^{2}$ John Innes Centre, Norwich, United Kingdom \\ *e-mail: akerke.amalova@gmail.com

\section{Phenotypic variation of common wheat mapping population Pamyati Azieva x Paragon in south-east of Kazakhstan}

\begin{abstract}
Development of mapping populations (MP) of any crop, including wheat, with its high-density genetics map is a crucial initial step in breeding programs aimed towards identification of quantitative trait loci for complex traits, such as yield. Current study is related to the field observations of hexaploid common wheat MP derived from a cross between the cultivars Pamyati Azieva (Russian Federation) and Paragon (UK). MP consisted of 98 recombinant inbred lines (RILs). It is the first mapping population to be constructed using one of the registered commercial cultivars in Kazakhstan. All 98 RILs were tested for four consecutive years (2015-2018) in the field conditions of the Kazakh Research Institute of Agriculture and Plant growing (KAZNIIZR). Field study suggests that the MP is a highly suitable genetic resource for wheat breeding projects, as the developed RILs showed a wide range of variation in yield related traits, including plant height (PH), number of fertile spikes (NFS), number of kernels per spike (NKS), and thousand kernel weight (TKW). The analysis of weight of kernels per plant (WKP) indicated that in total 40 RILs, including these five RILs: RIL48, RIL36, RIL83, RIL01, and RIL46, outperformed the local parent cultivar Pamyati Azieva. They showed averaged best yield values over the indicated period, which is highly correlated with PH, NFS, NKS, and TKW, as indicated by the Pearson correlation index. Individuals with favorable values for all yield-related traits were identified for their incorporation into the breeding studies. The GGE Biplot analysis allowed the separation of four trials to two mega-environments, possibly reflecting the amount of precipitation around flowering time and seed maturation time, which are crucial phases of wheat plant growth and development. These observations will be used to inform further studies related to genetic mapping of quantitative trait loci of yield components in common wheat.
\end{abstract}

Key words: wheat, recombinant inbred lines, mapping population, yield components, genotypeenvironment interaction.

\section{Introduction}

Wheat (Triticum aestivum L.) is a member of the Poaceae family, comprised of the major cereal grains, including maize and rice [1]. Among the food crops, wheat is one of the most abundant sources of energy and proteins for the world population and its increased production is essential for food security of our country as well as on the global range. Wheat occupies about $17 \%$ of the total cropland and contributes around $35 \%$ of the common staple food in many countries [2].

Increased demand for wheat at the international as well as internal market is requiring improvements in Kazakhstani wheat breeding programs. The global food market incentivizes Kazakhstan as an important producer and exporter of wheat, strengthening its position and promoting wheat production [3]. However, Kazakh wheat production is conducted under adverse weather conditions, and therefore, yields are lower than in other major wheat producing countries [4]. In addition, producers seem to face other constraints, such as weak infrastructure, remoteness from principal markets and a restrictive institutional environment [5]. Relative wheat production has been declining in the last fifty years, conveying that Kazakh wheat share has not been keeping pace with the global wheat production rates. Encouragingly, in the last decade, the rate of decline is slowing down, suggesting improvements in the Kazakh wheat production [6].

According to the data presented by the Ministry of Agriculture of the Republic of Kazakhstan, from the 2018 harvest, the total weight was 22.8 million 
tons, and average yield was $15.1 \mathrm{t} / \mathrm{ha}$. In general, the gross harvest of grain exceeds the last year's level by 760 thousand tons, or 3\%, and the yield has inceased by $0.6 \mathrm{t} / \mathrm{ha}$ or $4 \%$ [7].

The success of wheat growth is also largely dependent on the local breeding projects that focus on development of highly productive local cultivars. As agronomic traits of new cultivars, such as grain yield components, show continuous variation and are controlled by quantitative genes, the analysis of quantitative trait loci (QTL) is of great importance for plant breeders. The progress in genetic improvement of cereals over the last century was based mainly on the use of single genes with relatively clear-cut effects on the phenotype. Predicting genetic variances of biparental populations has been a long-standing goal for plant breeders. The ability to discriminate among crosses with similarly predicted high means, but different levels of genetic variance should improve the effectiveness of breeding [8]. Although it is possible to start breeding programs using only phenotypic selection, understanding the number and genomic location of genes controlling agronomically important traits can enhance the efficiency of selection [9]. The most widely used methods for identifying the marker-trait associations (QTL analysis) are genetic map construction, phenotyping and genotyping with the molecular markers, and use of differentiation populations [10; 11]. Experimental populations used for identifying the QTL in crops are $F_{2}$, backcrossed (BC1F1), recombinant inbred lines (RILs), and doubled haploid (DH) populations. DH populations are quicker to produce than RILs when methods to produce DH are available [12]. However, major disadvantage of $\mathrm{DH}$ is that recombination rate is less than that of RILs [13].

In breeding programs designed to increase grain yield, it is particularly important to make selections based on components and traits affecting yield. The yield components, which develop during ontogenesis, are the factors that determine the productivity of a wheat crop [14]. The contribution of each of these components in estimating the grain yield, though influenced by the genetic properties of a particular cultivar, can change depending on growth and development conditions, in particular under the influence of habitat and agronomic factors [15]. The individual yield components developed at different growth stages and the conditions prevailing during these stages are directly translated into the quantitative parameters of these traits.

Large number of quantitative traits in wheat, including kernel yield, flowering time, and resistance

Int. j. biol. chem. (Online) to various diseases, demonstrate significant variability in the manifestation of the genotype - environment interaction (GEI) [16]. Determining the nature of the ecological-genetic interaction or "genotypeenvironment" is one of the key tasks, the resolution of which is possible through the establishment of the mechanisms of inheritance of the genetic components of this system. Obviously, the phenotypic manifestation of quantitative traits depends on both genetic and non-genetic components that influence the formation of an individual or population genotype. Classical studies of quantitative traits assess the genotypeenvironment interaction, averaged, taking the action of the entire genome into account to a greater extent than the genome's individual loci or QTL [17].

As stated above, the development of bi-parental mapping populations is essential for the development of regional wheat breeding projects. Therefore, as part of the international project "ADAPTAWHEAT" [18], the genetic map from the cross of Pamyati Azieva (Russian cultivar registered in Kazakhstan) $\mathrm{x}$ Paragon (UK cultivar) was developed. The mapping population (MP) consisted of 98 recombinant inbred lines (RILs) [19]. As GEI is enormously influential to the yield and yield components, it was important to test the MP in Kazakhstani field conditions. The aim of the study was to evaluate the morphological variability of RILs in the southeast of the country.

\section{Materials and methods}

The subject of the study is a common wheat biparental mapping population (MP) from the cross of cultivars Pamyati Azieva (Russian Federation, registered in Kazakhstan) and Paragon (UK), hereafter referred to as Pam x Par. The Pam x Par MP consisted of 98 recombinant inbred lines (RILs) developed from $\mathrm{F}_{2}$ generation by single seed descent method in greenhouse conditions by using facilities of the John Innes Centre (Norwich, UK) from the period of 2011-2015 yy. By 2015, 98 RILs were available at $\mathrm{F}_{8}$ generation for field trials in Kazakhstan. MP along with the parent plants have been grown in the experimental station of the Kazakh Research Institute of Agriculture and Plant growing (KAZNIIZR, southeast of Kazakhstan). The station's GPS coordinates are $\mathrm{N} 43^{\circ} 13^{\prime} 09^{\prime \prime}$ E $76^{\circ} 41^{\prime} 17^{\prime \prime}$, altitude $740 \mathrm{~m}$. The cultivar Pamyati Azieva provides a combination of drought resistance, resistance to powdery mildew, and contains a large number of kernels per spike, which ensures high productivity per spike. Paragon served both conventional and organic growers well, and is recognized as a high bread making cultivar. In 
addition, Paragon has broad-spectrum disease resistance and good straw characteristics. The MP was developed under the project "ADAPTAWHEAT" [18].

Ninety-eight RILs ( $F_{8}$ generation) have been planted on the field of the KAZNIIZR in two randomized replications in 2015-2018 yy. The rows were spaced $15 \mathrm{~cm}$ apart and the distance between plants within a row was $5 \mathrm{~cm}$. In total, the data for mean values of eight agronomic traits of the 98 RILs harvested in four-year trials was analysed. The studied traits included plant height $(\mathrm{PH})$, peduncle length (PL), number of fertile spikes (NFS), spikes length (SL), number of kernels per spike (NKS), thousand kernels weight (TKW), weight of kernels per main spike (WKS), and weight of kernels per plant (WKP). Soil in the experimental field is light chestnut (humus 2.0$2.5 \%$ ). Annual precipitation at the experimental site ranged from 51 to $103 \mathrm{~mm}$ during the experiment, while the average temperature varied from 23 to $27^{\circ} \mathrm{C}$ (Figure 1).
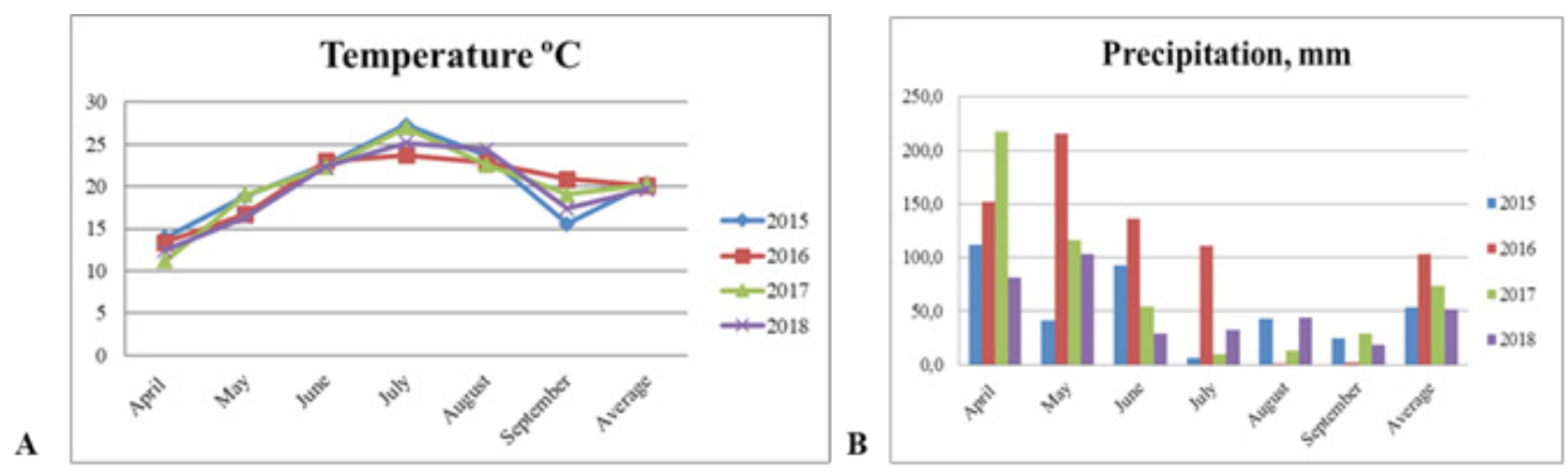

Figure 1 - Temperature (A) and Precipitation (B) data over the four years (2015-2018 yy.) at the KAZNIIZR breeding station

Statistical data analysis. Variability of key yield traits was assessed using Statistical Package for the Social Sciences Version 16.0 (SPSS software; International Business Machines: New York, USA, https://www.ibm.com/products/software). The descriptive statistics of all traits was measured during the experiment. The correlation analysis was calculated using GraphPad Prism Version 8.0 (GraphPad Software; La Jolla California, USA, https://www. graphpad.com/). The genotype-environment interaction (GEI) analysis was calculated using GenStat software Version 19.1 (VSN International, Hemel Hempstead: UK, www.vsni.co.uk).

\section{Results and discussion}

Yield performance of the MP. The value of WKP ranged from $2.3 \mathrm{~g}$ (RIL51) to $5.6 \mathrm{~g}$ (RIL48). The average WKP for the MP over the four years was $3.9 \pm 0.7 \mathrm{~g}$ and it was slightly less than WKP for Pamyati Azieva (4.1 g). In total, 40 out of tested 98 RILs exceeded the WKP in comparison with the parent cultivar Pamyati Azieva (Figure 2).

Results suggest that developed MP Pam x Par is well adapted to the local environmental conditions. RILs with the best yield performance are listed in

Int. j. biol. chem. (Online)
Table 1. The list suggests that those RILs can be successfully introduced to further breeding studies in south-east of Kazakhstan.

The WKP data from the Table 1 suggests that lines RIL48, RIL36, RIL83, RIL01, and RIL46 should be selected for extended field trials with larger field plots.

The Pearson correlation analysis indicates that WKP significantly correlated with PH, NFS, NKS, and TKW (Table 2).

As can be seen from the Table 2, the correlation indices were positive for all four traits, the analysis suggests that most high yielding accessions should be tall, with greater NFS, NKS and TKW numbers. Since the productivity of the studied population is largely dependent on weather conditions, which differed by year, the yield components were studied separately in all four years (2015-2018 yy.). The highest average WKP values were registered in 2016 and 2018. The average yield in 2016 was $4.6 \pm 0.13$ grams per spike and $4.3 \pm 0.11$ grams per plant in 2018. These results correlate with the amount of precipitation in July (Figure 1). Since wheat flowering and seed maturation occurs in July in south-east of Kazakhstan, precipitation in this month plays a crucial role in the final grain yield.

International Journal of Biology and Chemistry 12, № 1, 11 (2019) 


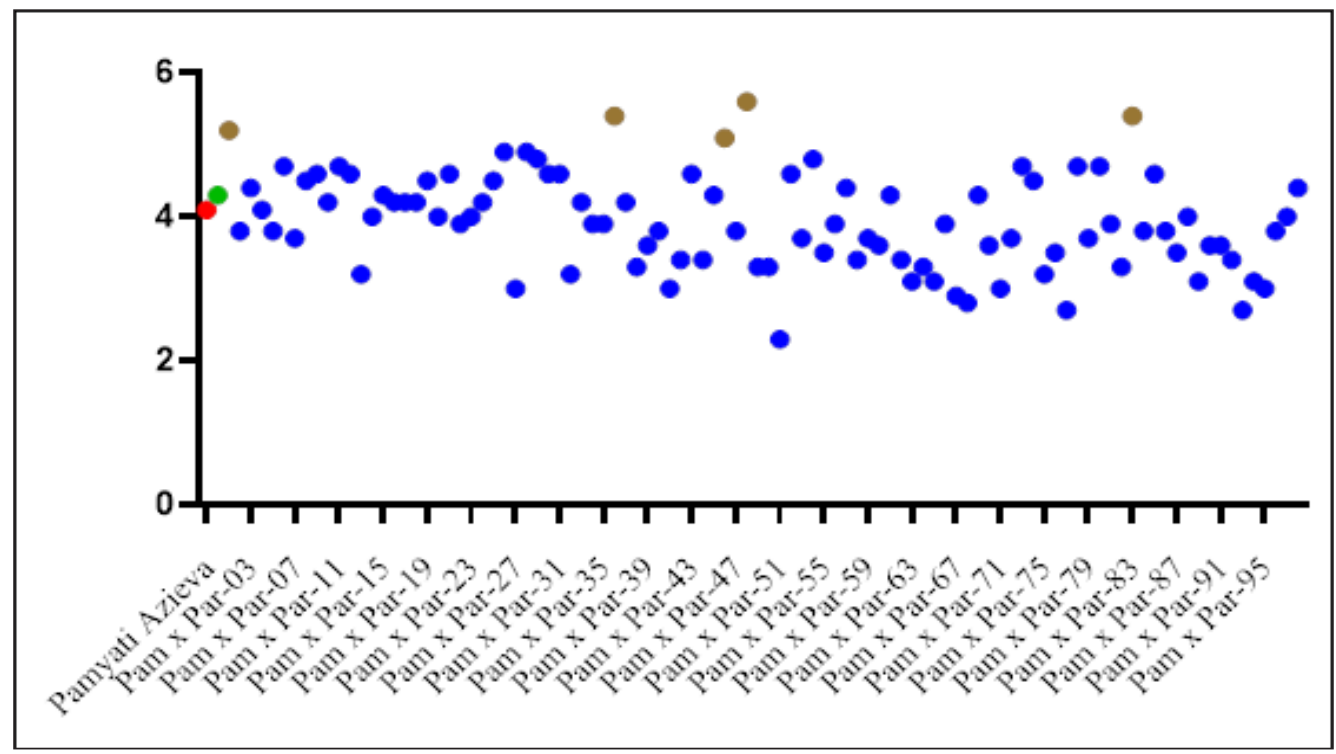

Figure 2 - The range of averaged WKP over the four years (2015-2018 yy.) in Pam x Par MP. Note: Pamyati Azieva - red colour, Paragon - green colour, RILs - blue colour. Brown colour designates RILs with the highest WKP values

Table 1 - List of RILs that showed best average values over four years (2015-2018) for three studied yield components, WKS, WKP, and TKW

\begin{tabular}{|c|c|c|c|c|c|}
\hline RILs & WKS (g) & RILs & WKP (g) & RILs & TKW (g) \\
\hline RIL83 & 1.8 & RIL46 & 5.1 & RIL98 & 33.3 \\
\hline RIL88 & 1.8 & RIL01 & 5.2 & RIL54 & 34.4 \\
\hline RIL25 & 1.9 & RIL83 & 5.4 & RIL57 & 34.6 \\
\hline RIL26 & 1.9 & RIL36 & 5.4 & RIL52 & 34.7 \\
\hline RIL52 & 1.9 & RIL 48 & 5.6 & RIL29 & 35.4 \\
\hline Pam & 1.3 & Pam & 4.1 & Pam & 30.6 \\
\hline Paragon & 1.7 & Paragon & 4.3 & Paragon & 25.7 \\
\hline Max* & 1.93 & Max* & 5.6 & Max* & 35.4 \\
\hline Min* & 0.97 & Min* & 2.3 & Min* & 19.6 \\
\hline Mean* & $1.47 \pm 0.02$ & Mean* & $3.9 \pm 0.07$ & Mean* & $28.6 \pm 0.29$ \\
\hline
\end{tabular}

Table 2 - Pearson correlation index for major yield-related traits in 98 RILs of Pam x Par MP

\begin{tabular}{|c|c|c|c|c|c|c|}
\hline Trait & PH & NFS & NKS & WKS & WKP & TKW \\
\hline NKS & $0.35^{* * *}$ & $0.12 \mathrm{~ns}$ & $1.00^{* * *}$ & $0.68^{* * *}$ & $0.47 * * *$ & $-0.14 \mathrm{~ns}$ \\
\hline WKS & $0.60^{* * *}$ & $0.03 \mathrm{~ns}$ & $0.68^{* * *}$ & $1.00^{* * *}$ & $0.66^{* * *}$ & $0.49 * * *$ \\
\hline WKP & $0.37 * * *$ & $0.54 * * *$ & $0.47 * * *$ & $0.66^{* * *}$ & $1.00^{* * *}$ & $0.40^{* * *}$ \\
\hline TKW & $0.40^{* * *}$ & $-0.06 \mathrm{~ns}$ & $-0.14 \mathrm{~ns}$ & $0.49 * * *$ & $0.40^{* * *}$ & $1.00^{* * *}$ \\
\hline
\end{tabular}

Note: $\mathrm{P}-$ values are provided with significance level indicated by the asterisks; $* \mathrm{P}<0.05, * * \mathrm{P}<0.001, * * * \mathrm{P}<0.0001, \mathrm{~ns}-$ not significant 
Despite the fact that yield in 2015 and 2018 was highest for the MP in the four subsequent years, the WKP was not interrelated (0.133). However, in all other cases the WKP significantly correlated with other trials. This result matches the GGE biplot analysis that graphically shows the relationship between genotypes and environments (Figure 3).

The genotype main effect and genotype $\mathrm{x}$ environment interaction (GGE) Biplot analysis suggests that environmental conditions in 2015 and 2016 were similar and combined in the first mega-environment (ME), and conditions in 2017 and 2018 were pooled in the second ME. In addition, the separation of four years trials into two mega-environments reflects the amount of precipitation in June (Figure 1), which is the key month for heading time in the southeast of the country.

The GGE Biplot graph (Figure 3) also suggests that the most suitable accessions for the first ME were RIL11, RIL25, and RIL46, while in the second ME - RIL25, RIL36, and RIL26, which match the data in the Table 1 well.

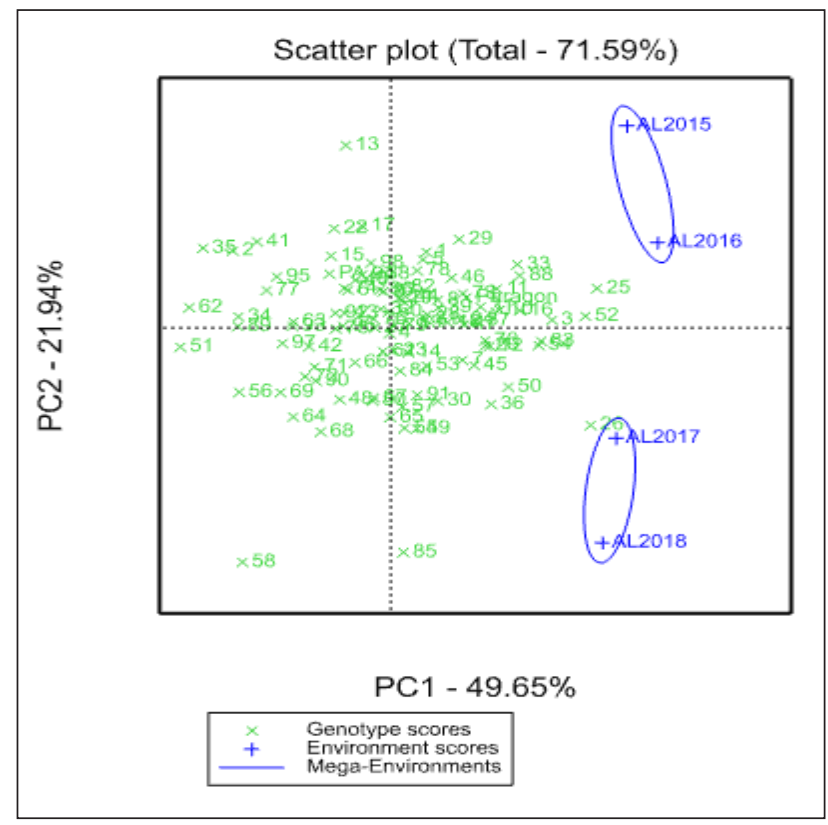

Figure 3 - The scatter plot of the GGE Biplot graph for 98 RILs of Pam x Par MP
A

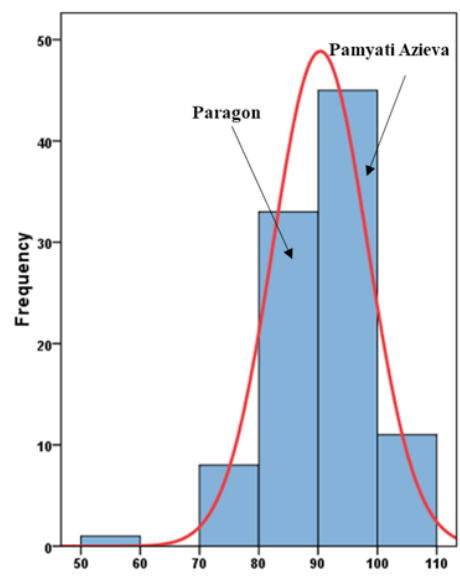

C

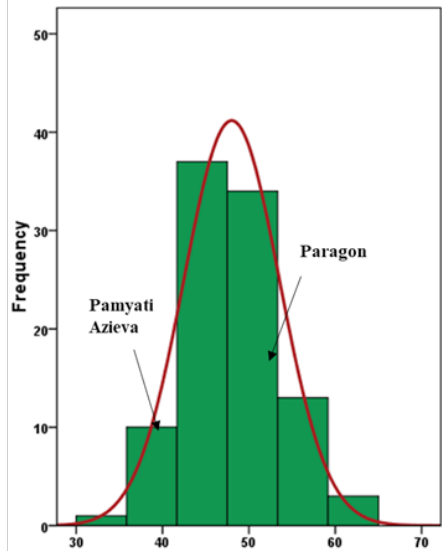

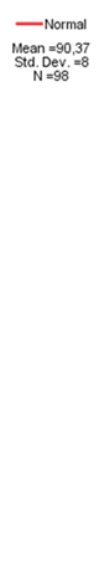

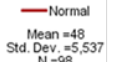

B

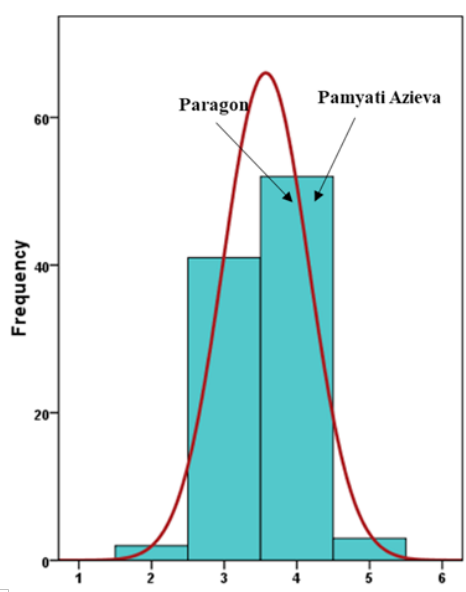

D

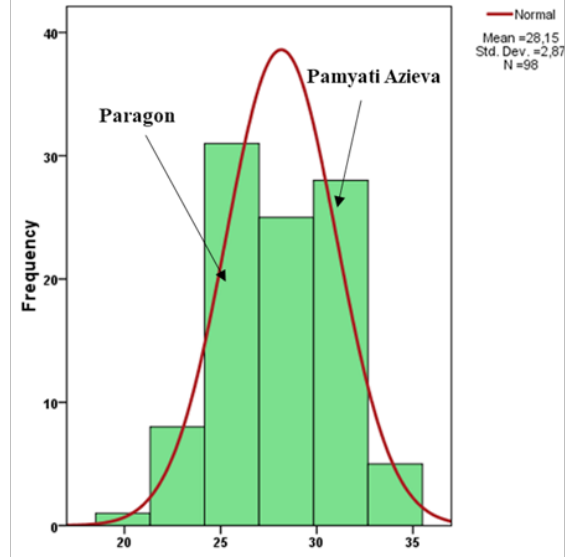

Figure 4 - The binomial distributions of major yield-related traits averaged over the four years (2015-2018 yy.) in Pam x Par MP. Note: A - plant height, B - number of fertile spikes, C - number of kernels per spike, D - thousand kernels weight 
Variability in the main yield components. The Pearson correlation indices suggest that PH, NFS, NKS and TKW are major yield components for the studied region (Table 2), variation of these four traits was observed in the Pam $x$ Par MP. It was found that PH ranged from $58.9 \mathrm{~cm}$ in RIL51 to $105.5 \mathrm{~cm}$ in RIL 49 (Figure 4.A). The PH of Pamyati Azieva was higher than in Paragon, and most of the RILs were in the range of $85 \mathrm{~cm}$ to $95 \mathrm{~cm}$ (Figure 4, A). The NFS ranged from 2.0 in RIL58 to 6.0 in RIL01, and the parents of the MP were similar in PH (Figure 4, B). However, when the parents were compared for NKS, Paragon (59.0) significantly outperformed Pamyati Azieva (42.0, $\mathrm{P}<0.0001$ ) (Figure 4, C), which suggests that UK standard is well suited to use in breeding for $\mathrm{PH}$, one of the important yield components. The TKW, another important yield trait, ranged from $19.6 \mathrm{~g}$ in RIL22 to $35.4 \mathrm{~g}$ in RIL29 (Figure 4, D). In contrast with NKS, in study of TKW, the cultivar Pamyati Azieva (30.6 g) showed significantly higher value $(\mathrm{P}<0.0001)$ than Paragon $(25.7 \mathrm{~g})$.

In overall, the assessment of the range of all four yield related components allowed the selection of valuable RILs that may play an important role in future wheat breeding studies in the region. The study allowed the identification of high yield RILs that may significantly contribute to the improvement of yield in southeast of the country. In addition, the variation of the field data can be successfully used in further studies related to the identification and genetic mapping of quantitative trait loci of yield related traits.

\section{Conclusion}

This study reports the field evaluation of the MP (98 RILs of Pam x Par) of common hexaploid wheat generated from the collaboration between Kazakh and British scientists. This is the first MP to be constructed by using one of the registered commercial cultivars in Kazakhstan. All 98 RILs were tested over the four consecutive years (2015-2018 yy.) at the KAZNIIZR breeding station. The field study suggests that the MP is a highly suitable genetic resource for wheat breeding projects, as developed RILs show a wide range of variation in yield related traits, including PH, NFS, NKS and TKW. The analysis of WKP indicated that in total 40 RILs outperformed the local parent cultivar Pamyati Azieva, including those five RILs (RIL48, RIL36, RIL83, RIL01, and RIL46) that showed averaged best yield values over the four years (2015-2018 yy.). The Pearson correlation index indicated that the average yield over all the four years was highly correlated with PH, NFS,

Int. j. biol. chem. (Online)
NKS, and TKW. Individuals with favorable values for all yield-related traits were identified for their incorporation into the breeding studies. The GGE Biplot analysis allowed the separation of four trials to two mega-environments. It was hypothesized that the separation reflects the amount of precipitation in flowering and seed maturation times, which are crucial phases of wheat plant growth. Finally, all obtained observations will be used for further studies related to genetic mapping of quantitative trait loci of yield components in common wheat.

\section{Acknowledgment}

This study was supported by "ADAPTAWHEAT" project funded by the $7^{\mathrm{TH}} \mathrm{EU}$ FP and the project "Creation of new DNA markers of drought resistance of spring wheat grown in the conditions of Northern Kazakhstan" (state registration number of the project 0118РК01352) under the budget program 0.0888 "Selection and seed production of drought-resistant, productive, high-quality varieties of spring wheat on the basis of classical methods of selection and modern approaches of biotechnology for the conditions of Northern Kazakhstan" (BR06249219) for 20182020 yy.

\section{References}

1 Michael J. (2009) The Wheat Crop. Wheat: Chemistry and Technology, Elsevier, 4th ed., Ch.2, pp. 19-49, ISBN: 978-1-891127-55-7.

2 Mitikul A., Regassa T. (2019) Participatory evaluation of bread wheat (Triticum aestivum L.) varieties for its yield performance at Madda Wlabu district of Bale Zone, South Eastern Ethiopia. J Eq. Sci. Sustain. Dev., vol. 3, no. 1, pp. 84-89.

3 Fellmann T., Hélaine S., Nekhay O. (2014) Harvest failures, temporary export restrictions and global food security: the example of limited grain exports from Russia, Ukraine and Kazakhstan. Food Sec., vol. 6, no. 5, pp. 727-742.

4 Gupta R., Kienzler K., Martius C., Mirzabaev A., Oweis T., de Pauw E., Qadir M., Shideed K., Sommer R., Thomas R., Sayre K., Carli C., Saparov A., Bekenov M., Sanginov S., Nepesov M., Ikramov R. (2009) Research Prospectus: A Vision For Sustainable Land Management Research In Central Asia. ICARDA Central Asia and Caucasus Program. Sustainable Agriculture in Central Asia and the Caucasus Series, no.1, p. 84.

5 Edinaldo T. (2018) The Impacts of El Niño and La Niña on Large Grain Producing Countries in 
ECA: Yield, Poverty and Policy Response. Economics Faculty Journal Articles, pp. 1-78.

6 Report prepared under the FAO/EBRD cooperation (2012) Challenges in enhancing agricultural and food production, $182 \mathrm{p}$.

7 FAS staff (2018) Kazakhstan grain and feed update report, $11 \mathrm{p}$.

8 Mohammadia M., Tiedebc T., Smith K. (2015) PopVar: A Genome-Wide Procedure for Predicting Genetic Variance and Correlated Response in Biparental Breeding Populations. Crop Sci., vol. 55, no. 5, pp. 2068-2077. doi: 10.2135/cropsci2015.01.0030

9 Heidari B., Sayed-Tabatabaei B., Saeidi G., Kearsey M., Suenaga K. (2011) Mapping QTL for grain yield, yield components, and spike features in a doubled haploid population of bread wheat. Genome, vol. 54, no. 6, pp. 517-527. doi: 10.1139/g11017.

10 Lörz H., Wenzel G. (ed.) (2004). Molecular marker systems in plant breeding and crop improvement. Biotechnol. Agric. For., Springer-Verlag, Ch. $55,476 \mathrm{p}$.

11 van Eeuwijk F.A., Bink M.C., Chenu K., Chapman S.C. (2010) Detection and use of QTL for complex traits in multiple environments. Curr. Opin. Plant Biol., vol. 13, no. 2, pp. 193-205. doi: 10.1016/j.pbi.2010.01.001

12 Newbury H.J. (2003). Plant molecular breeding, Biological sciences series, Blackwell, Ch.12, 265 p., ISBN 1-84127-321-X.

13 Guan H., Farhan A., Qingchun P. (2017) Dissection of recombination attributes for multiple maize populations using a common SNP assay. Front Plant Sci., vol. 8, p. 2063. doi: 10.3389/fpls.2017.02063
14 Singh S.P., Diwivedi V.K. (2002) Character association and path analysis in wheat (Triticum aestivum L.). Agric. Sci. Dig., vol. 22, no. 4, pp. 255257.

15 Sainis J.K., Shouche S.P., Bhagwat S.G. (2006) Image analysis of wheat grains developed in different environments and its implications for identification. J. Agric. Sci., vol. 144, pp. 221-227. doi: $10.1017 / \mathrm{S} 0021859606006010$

16 Bariana H.S., Bansal U.K., Schmidt A., Lehmensiek A., Kaur J., Miah H, Howes N., McIntyre C.L. (2010). Molecular mapping of adult plant stripe rust resistance in wheat and identification of pyramided QTL genotypes. Euphytica, vol. 176, no. 2, pp. 251-260. doi: 10.1007/s10681-010-0240-x

17 Börner A., Schumann E., Fürste A., Cöster H., Leithold B., Röder S., Weber E. (2002) Mapping of quantitative trait loci determining agronomic important characters in hexaploid wheat (Triticum aestivum L.). Theor. Appl. Genet., vol. 105, pp. 921-936. doi: 10.1007/s00122-002-0994-1

18 European Commission (2012-2015). Genetics and physiology of wheat development to flowering: tools to breed for improved adaptation and yield potential. URL: https://cordis.europa.eu/project/ $\mathrm{rcn} / 101673 /$ factsheet/en.

19 Yermekbayev K., Turuspekov Y., Ganal M., Plieske J., Griffiths S. (2017) Construction and utilization of the hexaploid map Pamyati Azieva x Paragon Plant Genetics, Genomics, Bioinformatics and Biotechnology. p. 119. In: Proceedings of the 4th International conference "Plant Genetics, Genomics, Bioinformatics and Biotechnology" (PlantGen2017), Turuspekov Y. \& Abugalieva S. (eds.). Almaty, Kazakhstan. 